\title{
Identifying Basal Nighttime Radiance Levels for Estimating Traffic Flow based on VIIRS/DNB data
}

\author{
Identificação de Nível de Radiância Noturna Basal para a Estimativa de Tráfego \\ Rodoviário a partir de Dados VIIRS/DNB
}

Gabriel Da Rocha Bragion 1, Gabriel Crivellaro Gonçalves ${ }^{2}$, Ana Paula Dal'Asta ${ }^{3}$, Ana Carolina De Faria Santos ${ }^{4}$, Lucas Maia De Oliveira ${ }^{5}$, Antônio Miguel Vieira Monteiro ${ }^{6}$, Silvana Amaral ${ }^{7}$

1 INPE - National Institute for Space Research, Earth Observation and Geomatics Division, São José dos Campos, Brazil. gabriel.bragion@hotmail.com

ORCID: https://orcid.org/0000-0003-3875-4986

2 INPE - National Institute for Space Research, Earth Observation and Geomatics Division, São José dos Campos, Brazil. gabriel.goncalves@inpe.br

ORCID: https://orcid.org/0000-0003-4251-4790

3 INPE - National Institute for Space Research, Earth Observation and Geomatics Division, São José dos Campos, Brazil. apdalasta@gmail.com

ORCID: https://orcid.org/0000-0002-1286-9067

4 VP Ecologia Empresarial Ltda, Environmental Licensing and Management Division, Taubaté, Brazil. anacarolina.fs@outlook.com ORCID: https://orcid.org/0000-0003-0524-8892

5 UNICAMP - State University of Campinas, Elza Berquó Center for Population Study, Campinas, Brazil. lucas.luckes@gmail.com ORCID: https://orcid.org/0000-0001-9714-2619

6 INPE - National Institute for Space Research, Earth Observation and Geomatics Division, São José dos Campos, Brazil. miguel.monteiro@inpe.br ORCID: https://orcid.org/0000-0003-1477-1749

7 INPE - National Institute for Space Research, Earth Observation and Geomatics Division, São José dos Campos, Brazil. silvana.amaral@inpe.br ORCID: https://orcid.org/0000-0003-4314-7291

\begin{abstract}
The recent COVID-19 outbreak drove the attention to methods for monitoring the flow of people between human settlements, including traffic flow. Although the remote sensing of nighttime lights is a viable option to estimate traffic flow-derived indicators, changes in radiance levels at night are not all associated with traffic. This paper presents the theoretical approach proposed on the development of an algorithm able to identify spectrally unbiased control samples for regions of interest (ROI), namely roadway sections. Firstly, an experiment is presented to put in evidence the background dependency of the DNB monthly composites (vcm) radiance levels. Then, an overview of the algorithm is presented, followed by an empirical estimation of its time complexity. The results showed that the algorithm has an $\mathrm{O}(\mathrm{n})$ time complexity and that control samples and ROIs can have similar time series features, indicating that analysis without the use of control samples can lead to biased results.
\end{abstract}

Keywords: VIIRS. MODIS. Time-series. Anthropogenic Lights.

Resumo: O recente surto de COVID-19 colocou em evidência a busca por métodos para o monitoramento do fluxo de pessoas entre assentamentos humanos, incluindo o fluxo via veículos automotores. Embora o sensoriamento remoto de luzes noturnas seja uma opção viável para estimar indicadores derivados do fluxo de veículos, variações nos níveis de radiância durante a noite não são estritamente associadas com o tráfego. Este trabalho apresenta a abordagem teórica proposta para o desenvolvimento de um algoritmo capaz de identificar amostras de controle espectralmente não-enviesadas para regiões de interesse (ROI), neste caso, trechos rodoviários. Primeiramente, um experimento é apresentado para expor evidências relativas à dependência dos níveis de radiância das composições mensais DNB ( $\mathrm{vcm}$ ) em relação ao background associado aos trechos rodoviários. Então, após a uma breve apresentação da cadeia lógica do algoritmo, a complexidade de execução do algoritmo foi empiricamente estimada. Os resultados mostram que o algoritmo tem uma complexidade estimada $\mathrm{O}(\mathrm{n})$, e que amostras de controles e regiões de interesse apresentam características fundamentais similares em alguns casos, indicando que a análise das composições mensais DNB sem a consideração de amostras de controle pode levar a resultados enviesados.

Palavras-chave: VIIRS. MODIS. Séries Temporais. Luzes Antropogênicas. 


\section{INTRODUCTION}

Typifying and monitoring regional road traffic spatiotemporal patterns might be crucial to better understand the possibilities of COVID-19 spread between human settlements. The monitoring of phenomena associated with the road traffic via remotely sensed data is mostly restricted to very high-resolution sensors or on-road measurements, which are often neither accessible nor systematically distributed (TUERNER et al., 2013). Some studies exploited images and composites from the Visible Infrared Imaging Radiometer Suite (VIIRS) - Day/Night Band (DNB) to successfully detect and monitor light sources at night at a sub-pixel level, such as boats, gas-flares, and biomass burning (ELVIDGE et al., 2015a; POLIVKA et al., 2016; ELVIDGE et al., 2015b). Although DNB-derived data have been successfully used in these approaches, the estimation of traffic-related metrics through it is limited to regional scales (CHANG et al., 2019). Road traffic lights can be relatively dim and arguably hard to resolve from space, given the anisotropic factor and oblique emission angles of auto headlights (KYBA et al., 2014). Therefore, the characterization of spatiotemporal patterns associated with road traffic radiance at night would be more robust if supported by methods for identifying patterns strictly associated with environmental changes, rather than the road traffic itself.

Albeit diverse, on-road sensors are most usually fixed and used for monitoring and fining purposes. Despite registering the total number of vehicles along a roadway section in a very fine spatial and temporal resolution, this type of sensor is not to be found in many smaller roadways. Smaller roadways are often the only vehicle route available to less prominent towns and play an important role in the spreading of contagious diseases to areas that are closer to the base of the human settlement hierarchy (FORTALEZA et al., 2020). The use of satellite remote sensing methods comes in handy, for it can produce spectral information in a regular and extensive form, surpassing the drawbacks of the on-road driven methods.

Although daytime high-resolution imagery matches these criteria, studies of this sort are mostly focused on object-oriented techniques, limiting the recognition of features that have a similar spatial scale to a given sensor ground sample distance (GSD) (BATZ; SCHAPE, 2000). High-resolution imagery still has a high cost of acquisition, generally covering areas only on demand, and lacking the higher availability usually met by moderate resolution sensors. However, sub-pixel target detection based on the reflectance factor analysis, through moderate resolution sensors, usually requires a higher spectral resolution (CHANGE; HEINZ, 2000). In this sense, the detection of targets at night is a suitable approach, for it does not depend on a higher spectral resolution, neither a finer GSD.

Target detection from nightly imagery is mostly based on the expected level and frequency of radiance associated with optical radiation sources (ELVIDGE et al., 2015). The level of radiance from headlights measured by the DNB sensor can be lower than the level expected from other typical artificial light sources, potentially lower than high albedo features and background radiation rising from areas around lit sites (KYBA et al., 2014). Chang et al. (2019) presented a study analyzing the correlation between traffic flow and a DNB derived metrics from accumulated pixels overlapping freeways in China, and found out a broad correlation degree ( $\mathrm{R}^{2}$ ranging from 0.267 to 0.818 ), depended on the metric and vehicle type. Despite the outcome, factors like the higher density of roadhouses on higher flow freeways could lead to similar results, putting in check the assumption that these correlations are strictly due to the vehicle flow; most likely the reason why the authors refer to it as traffic prosperity.

Previous studies showed that the monthly nighttime lights (NTL) average radiance is correlated to factors like the vegetation cover and changes in albedo; and that some of these influences can be found even in the annual NTL composites (LEVIN, 2017; LEVIN; ZHANG, 2017). To identify different spatiotemporal patterns of road traffic from the monthly NTL composites, one must first investigate what is the contribution of other side parameters to the changes observed in the average radiance levels at night. Part of this problem could be analyzed by comparing the monthly average radiance associated with pixels lacking the presence of light sources to pixels overlapping roads of similar spectral response. This paper presents the theoretical approach applied for the development of an algorithm able to identify spectrally unbiased unlit areas. These areas shall be used as control samples of the radiance levels from roadway sites, allowing a systematic estimation of the basal radiance level of a given roadway. An analysis of the empirically estimated time complexity is presented, given that early drafts of the code tended to present an exponential time complexity 
growth.

\section{MATERIAL AND METHODS}

\subsection{Study Area}

The Metropolitan Region of the Paraíba Valley and North Coast (RMVPLN) is located in the State of São Paulo and, along the BR-116 highway, it connects the metropolitan regions of São Paulo (RMSP) and Rio de Janeiro (RMRJ) (Figure 1). The region comprises 39 municipalities divided into five subregions, holding a high variety of economic activities and a heterogeneous demographic distribution, most concentrated in the urban areas (GOMES; RESCHILIAN; UEHARA, 2018). In a fresh reading of the RMVPLN centered regional planning, Gomes, Reschilian, and Uehera (2018) pointed out that the strategic location of the RMVPLN seemed to lead the political vision for development towards the exploiting of the distinct local advantages in a competitive way. Although logic, without the population, society, and political engagement, this historical approach for the development resulted in sub-regional inequalities, without the carrying for the urban-regional needs as well. Smaller town workers often adopt a daily routine of traveling across different municipalities in carpool systems or public transportation, increasing the probability of transmission and spreading of the COVID-19 from hub cities to smaller towns.

Figure 1 - Municipalities of the Metropolitan Region of the Paraíba Valley and North Coast. $46^{\circ} 15^{\prime} \mathrm{W}$ $45^{\circ} \mathrm{W}$
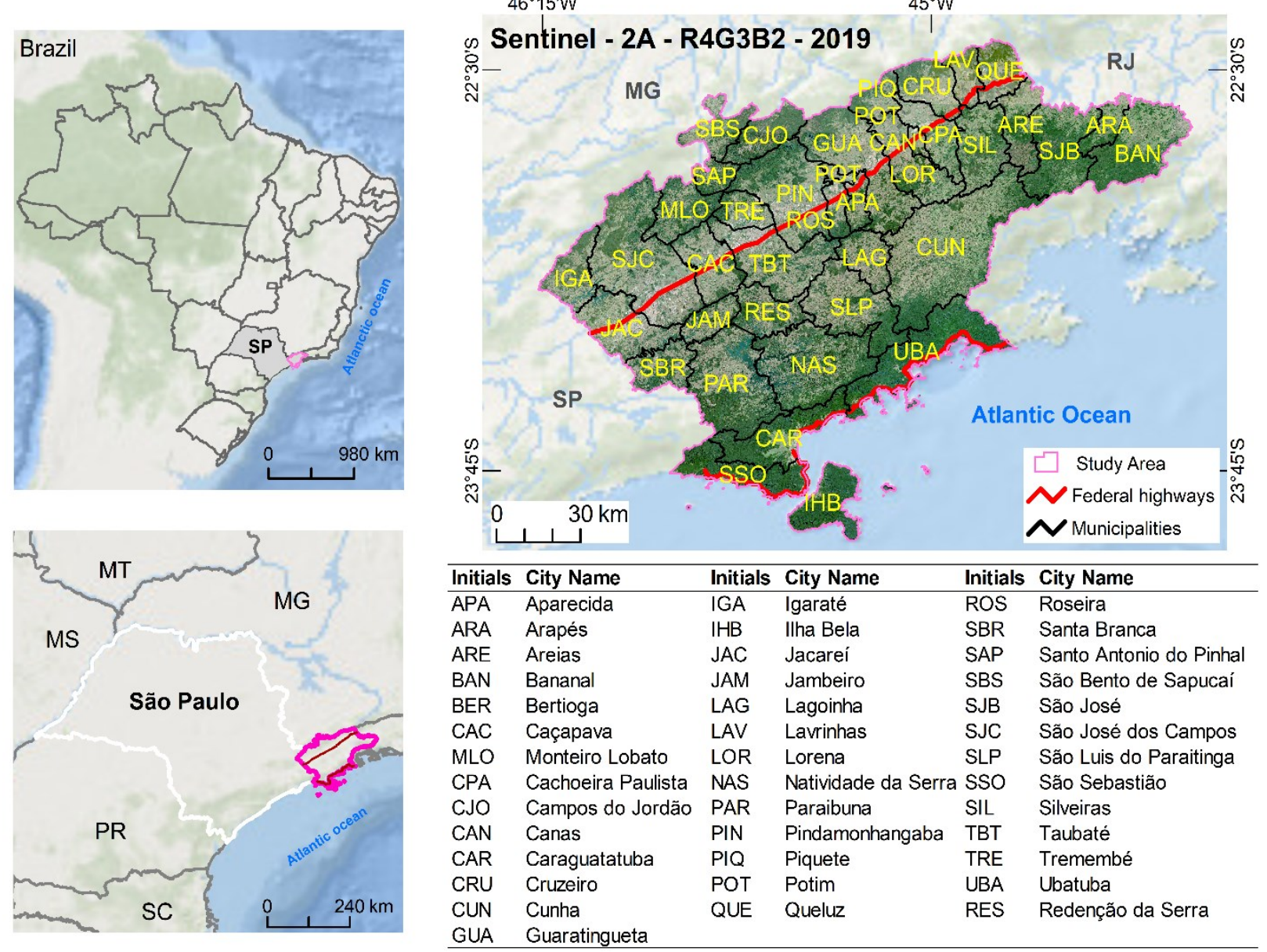

Source: The Authors (2021).

\subsection{Data acquisition and algorithm procedural approach}

Firstly, roadway sections, namely Regions of Interest (ROI), were manually selected considering the functional role of the section, prioritizing roadways that give access to the municipalities but are not embedded in the lit urban area. In a general form, ROIs are clusters of pixels overlapping a roadway section. Currently, 
each ROI comprises nine pixels and can sum up to $5.9 \mathrm{~km}$ of a roadway. A larger number of pixels would result in a higher spectral mixture, making it difficult to search and validate a control sample.

Monthly cloud-free nightly composites ("vcm" version), which were the main input data of this work, are processed and made available by the Earth Observation Group (EOG), at Payne Institute for Public Policy website (https://eogdata.mines.edu/download_dnb_composites.html). The composites represent the monthly average radiance at the surface from daily cloud-free, low-moonlight pixels from images retrieved by the DayNight Band (DNB) sensor. The Visible Infrared Imaging Radiometer Suite's (VIIRS) DNB sensor, onboard the joint NASA/NOAA Suomi National Polar-orbiting Partnership (Suomi NPP) satellite, retrieves visible daily radiance levels at night, approximately at $1 \mathrm{~h}: 30 \mathrm{~min}$, local time. The DNB sensor collects data on a constant $742 \times 742 \mathrm{~m}$ footprint, but its monthly composites are binned to a global 15 arc-second geographic grid ( $\sim 63 \mathrm{~m}$ at the equator) (ELVIDGE et al., 2017).

Nightly sensed radiance values were needed for two different algorithm processes (Figure 2). First, they are required to assess the presence of light sources under a pixel's footprint. For this purpose, it was determined that every pixel with an average radiance level lower than $2 \eta \mathrm{W} \cdot \mathrm{cm}^{-2} \cdot \mathrm{sr}^{-1}$ is to be considered as a potential sample by the algorithm, a value judged as conservative and higher than the average background radiance for latitudes between 10 and $50^{\circ}$ (ELVIDGE et al., 2017). Secondly, they are the main input to determine the nominal radiance level of a roadway section.

Figure 2 - Annual Average Nighttime Radiance of the Metropolitan Region of the Paraíba Valley and North Coast.

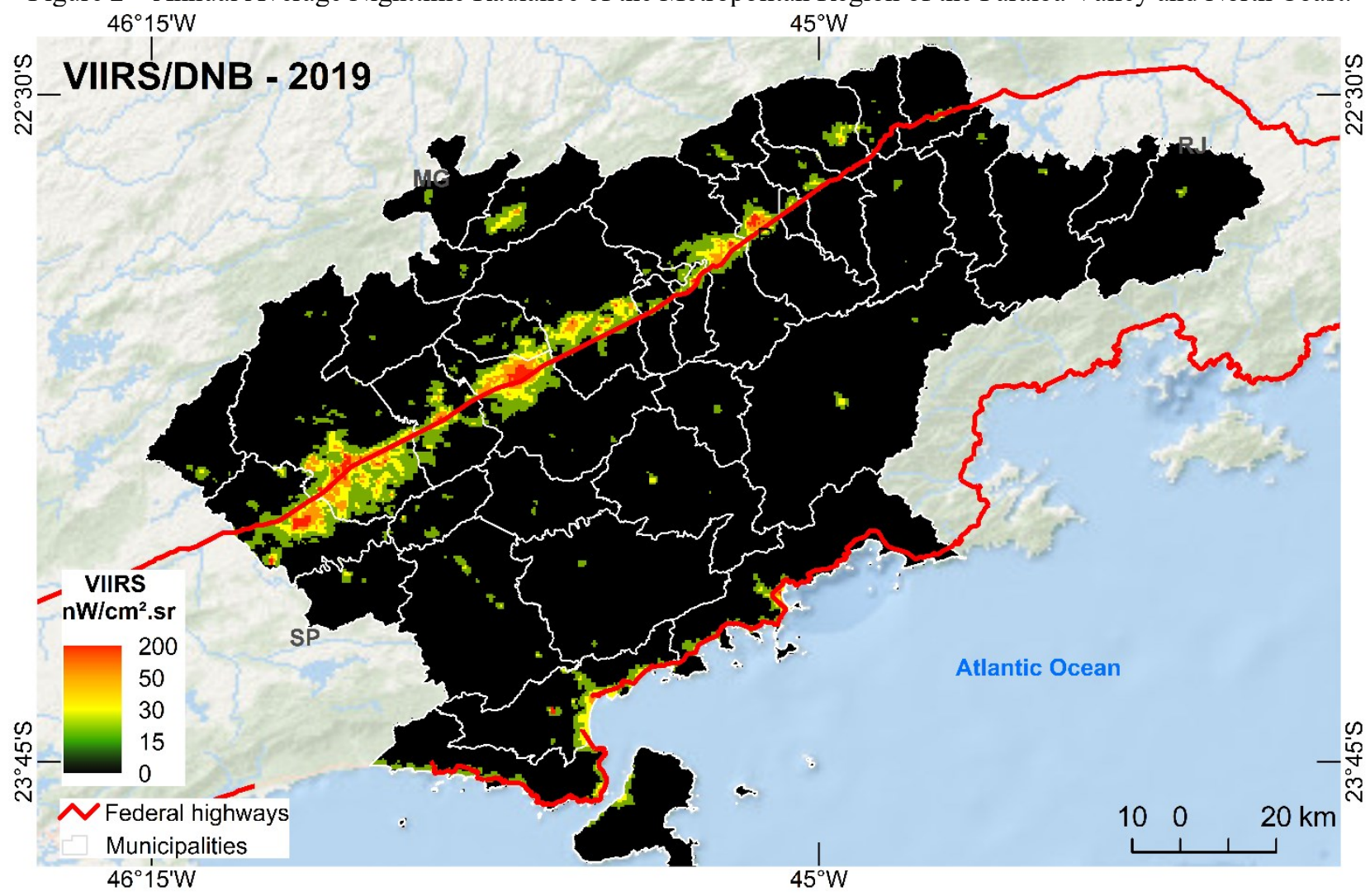

Source: The Authors (2021).

Road network data was retrieved from the National Cartographic Base, made available by the Brazilian Institute for Geography and Statistics (IBGE) (IBGE, 2019). Surface reflectance values were extracted from the MODIS MCD43A4 collection, band 1 (620-670nm), band 2 (841-876nm), and band 4 (545-565nm), a collection of images containing the best pixels of a 16-days-moving-window that have been modeled as if they were taken from a nadir instantaneous field of view (SCHAAF and WANG 2015). The selected bands correspond to all the available bands in between the VIIRS/DNB spectral range (500 - 900nm). To increase the probability of high-quality pixels and proceed with the analysis with more temporal compatible data, the quality assessment (QA) band of the MCD43A4 collection was consulted to produce a 30-day single composite for each month, ranging from January 2013 to January 2020. Finally, the processed MCD43A4 30-day images 
were reprojected to match the VIIRS/DNB grid.

Although unlit roadways might be the closest available targets to be selected as control samples, a preliminary analysis showed that the magnitude of a cluster of pixels' radiances values overlapping a roadway can be as dim as completely unlit areas, in some cases. Moreover, there is no general optimal radiance value to specify if there are no light sources in a roadway, since traffic, noise, and background radiance values are not stationary, both in space and time (ELVIDGE et al., 2017). Therefore, the algorithm must automatically assume that a pixel overlapping a roadway can't be elected as a control sample.

VIIRS/DNB monthly NTL composites, MCD43A4 surface reflectance, and road network data are ingested into the algorithm (Figure 3a). Once the datasets are processed, the MCD43A4 data is associated with a ROI (Figure 3b). The goal of the algorithm is to find a cluster of $3 \times 3$ pixels, namely a control sample candidate, with the closest spectral response to a specific ROI sample, given a series of restrictions (Figure $3 \mathrm{c}$ and 3d). The proceedings illustrated in Figure 3 were implemented in a Python 3.5 environment.

Figure 3 - Flowchart of the proposed algorithm.

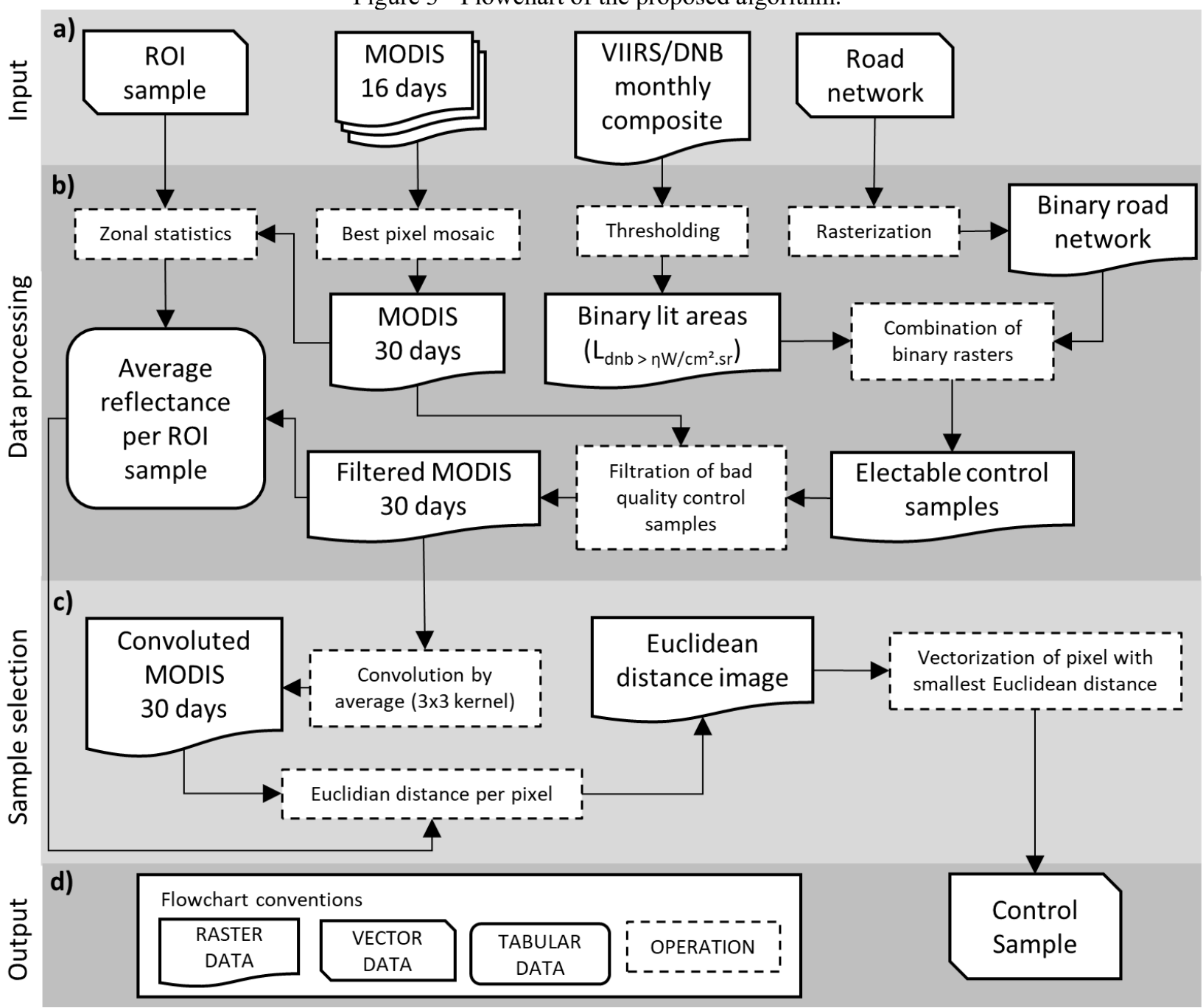

Source: The Authors (2021).

The spectral response is represented by the average reflectance of a control sample candidate or ROI, based on the processed MCD43A4 bands, while its likelihood is given by the Euclidean distance between those metrics (Eq. 1).

$$
\tilde{\lambda}=\sqrt{\left(\overline{B 1}_{R O I}-\overline{B 1}_{c t r l}\right)^{2}+\left(\overline{B 2}_{R O I}-\overline{B 2}_{c t r l}\right)^{2}+\left(\overline{B 4}_{R O I}-\overline{B 4}_{c t r l}\right)^{2}}
$$

where $\tilde{\lambda}$ is the spectral likelihood, $\overline{B n}_{R O I}$ is the ROI's average reflectance from the $\mathrm{n}$-th band of the MCD43A4 product, and $\overline{B n}_{c t r l}$ is the control sample's average reflectance from the n-th band of the MCD43A4 product. 
Apart from the restrictions aforementioned, a control sample must not contain an invalid pixel. An invalid pixel is a pixel whose value doesn't have a true physical meaning, nor is contaminated, either due to instrument problems or cloudy atmosphere conditions during the acquisition of data. Based on these restrictions, the algorithm must test every sample candidate and then calculates their $\tilde{\lambda}$. Finally, the control sample candidate with the smallest spectral likelihood is elected as a control sample for that specific ROI, given a specific month.

Even though other studies have already pointed out the seasonality effect of changes in albedo over the monthly and annual NTL composites (LEVIN, 2017; LEVIN; ZHANG, 2017), these effects were observed in national or regional scales. The hypothesis underlying the motivation of the algorithm's construction relies on the possibility that the background setting of a roadway can significantly influence the radiance level sensed by the DNB.

To gather evidence of this possibility, a straightforward experiment is proposed, which consists of the intercomparison of the radiance levels of unlit areas with well-established typical spectral signatures. Firstly, three categories of land cover were elected: (1) Forest, including natural and cultivated forests; (2) Pasture, consisting of pasture areas and mosaics of pasture and temporary crops, and; (3) Waterbodies. These categories represent three main types of background that can be found around roadways in the study area. Land use and land cover (LULC) data were retrieved from the MapBiomas (MB) Collection (MAPBIOMAS, 2021). Secondly, LULC is generalized to the same spatial resolution and footprint of the DNB data, since MB data has a spatial resolution of $30 \mathrm{~m}$. Based on the DNB data, a grid cell was generated with all cells corresponding to the exact location and extension of the matching DNB pixels. The rules adopted for this generalization process are the following: (1) if a cell overlaps a roadway section or a persistent lit area, the cell is classified as "Others"; (2) if a DNB cell covers at least one MB pixel categorized as non-vegetated area, the cell is set to "Others". Other LULC classes are evaluated whenever these rules are not satisfied; (3) if $90 \%$ or more of a cell's area is covered by a single LULC class of interest (i. e., Forest, Pasture or Waterbody ${ }^{1}$ ), the cell is classified as the given class of interest preceded by "Unlit" (e. g., Unlit Forested Areas); (4) if a cell does not satisfy any of the aforementioned rules, the cell is also set to "Others".

The resulting grid was rasterized to a LULC map of the same spatial resolution of the DNB data, consisting of the following classes: (1) Unlit Forested Areas - Areas with more than $90 \%$ of Natural Forest and Forest Plantation; (2) Unlit Water Surface - Areas consisting of oceanic waters at least $1 \mathrm{~km}$ offshore; (3) Unlit Pasture Area - Areas with more than $90 \%$ of Pasture and Mosaic of Agriculture with Pasture ; (4) Others, consisting of areas with less than $90 \%$ of prevalence of any of the class of interest, permanent lit areas or roadway sections and non-vegetated areas; mainly associated with urbanized or construct areas of the study area. Each class of interest was used as a spatial reference to produce 300 random samples, a hundred for each class of interest. The DNB average values were ingested into the samples on a monthly basis from 2013 to 2019 and then averaged. The result is a single profile of DNB monthly radiance values for each class of interest.

\section{RESULTS AND DISCUSSION}

The results are presented as follows: (1) firstly, an intercomparison of the different time series of unlit areas is presented and discussed; (2) secondly, an overview of the algorithm is presented along with the results of the empirical time complexity estimation; (3) finally, a pair of representative time series of ROI are analyzed and compared with their control samples counterparts.

\subsection{DNB monthly composite background dependency}

Background dependency is a term chosen to represent the dependency of the average radiance levels of

\footnotetext{
${ }^{1}$ Because water surfaces are particularly affected by the overglow effect, all cells less than $1 \mathrm{Km}$ offshore or at the continent were classified as "Others" as well. This is a precaution procedure to avoid the sampling of water surfaces lit by anthropogenic light sources.
} 
the monthly DNB composites on the spectral characteristics of the surface under a target or light source, i. e., background. A background with an overall higher reflectance factor in the visible spectra should result in a higher level of average radiance. Figure 4 displays the time series of three classes of interest considered as unlit due to the arrangement of restrictions criteria applied. Since each time series corresponds to the averaging of a hundred samples, effects of the spectral bias due to individual LULC trajectories are minimized.

Figure 4 - Time series of the average Monthly DNB radiance from three classes of interest: Unlit Water Surfaces (blue), Unlit Forested Areas (green), and Unlit Pasture Areas (orange).

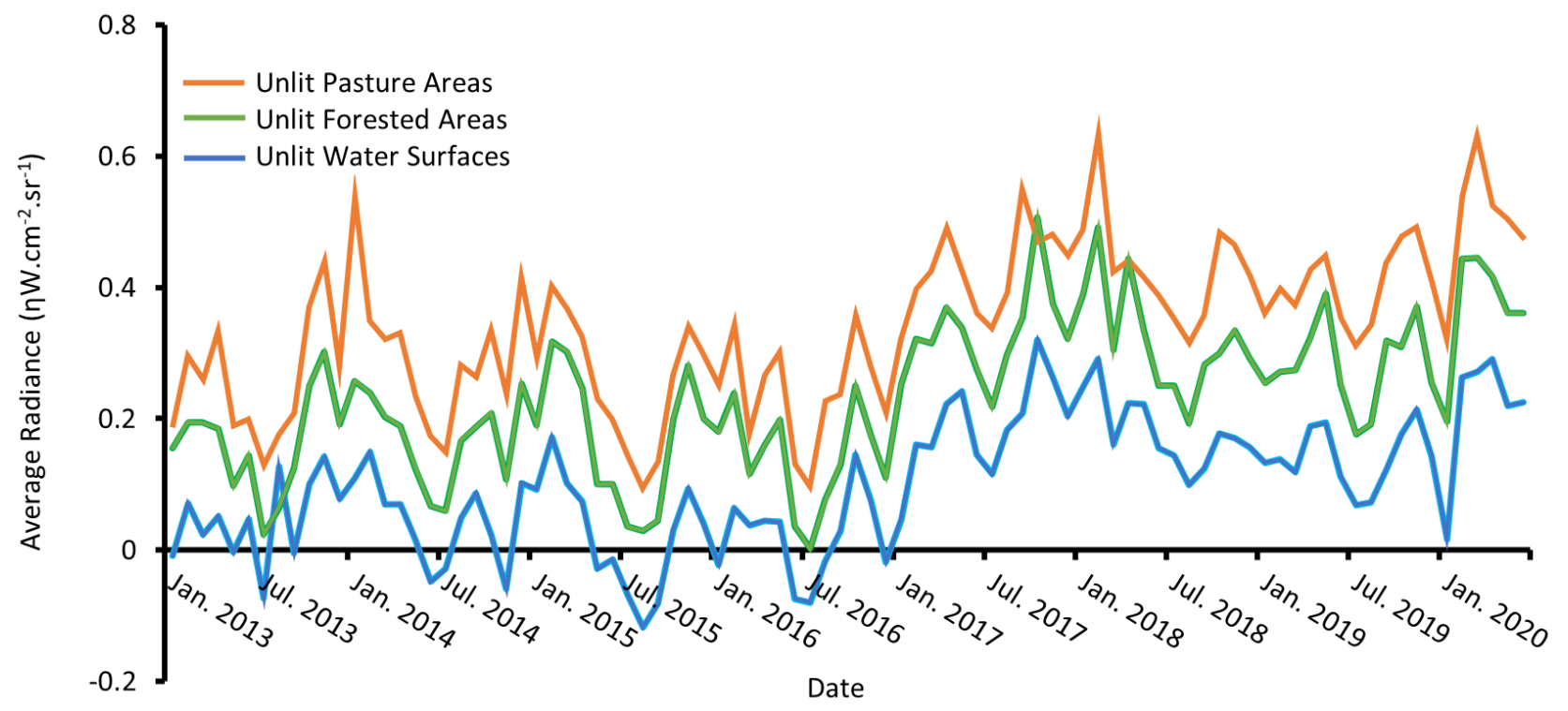

Source: The Authors (2021).

The DNB time series of each class are all similar. They present concurrent peaks and valleys, although their average values are consistently different. Those are indicators that the predicates under the algorithm definition are valid. The similar profiles imply that they are subjected to environmental and in-sensor variations that are dragged through the stages of processing the DNB images into monthly composites. Yet, the differences in the profiles' average values are present and consistent throughout the years, which indicates that each group of samples shares a similar unique feature; in this case, their reflectance factor.

Moreover, even if those observations alone do not fully support the hypothesis that monthly DNB values of unlit areas are still biased by their background, the spectral characteristics of the different groups of LULC's classes of interest allow further develop this idea. As expected, Unlit Pasture Areas have the higher levels of average DNB, most likely due to its typical higher reflectance factor, when compared to the other two classes elected. Right under the Unlit Pasture Areas' time series, lays the Unlit Forested Areas' time series, which has a typically lower reflectance factor than pasture areas and higher than water surfaces areas (KOKALY et al., 2019). There are seasons in which forests can suffer a greater influence of the background due to their decidual nature (HUETE; JACKSON; POST, 1985); but not in this case, since the natural forests of the study area are predominantly Dense Ombrophilous Forest (IBGE, 2019). The bottom time series represented by Unlit Water Surfaces has the smaller average DNB radiance values, as expected. It must be taken into account that only offshore water surfaces were sampled and that the results obtained are unlikely to be reproduced if inland smaller water features were sampled; not only because of the likely spectral mixture under the pixel's footprint but also because of the more frequent presence of sediments found in those targets (MOUW et al., 2015).

\subsection{Algorithm's time complexity and overview}

Profiling of the algorithm identified the functions related to the calculation of average radiances and reflectances as the most time-consuming ones. Both functions increase the number of operations as the number of images from different dates or samples is increased. Those specific operations are dependent on third-party 
functions, making it difficult to determine the complexity of the algorithm in a theoretical approach. Therefore, we empirically tested the time demanded by the algorithm while increasing the number of images and ROI in 90 different combinations (Figure 5).

Figure 5 - Algorithm's time demand for different conditions regarding the number of images and samples, and fitted multivariate linear model.
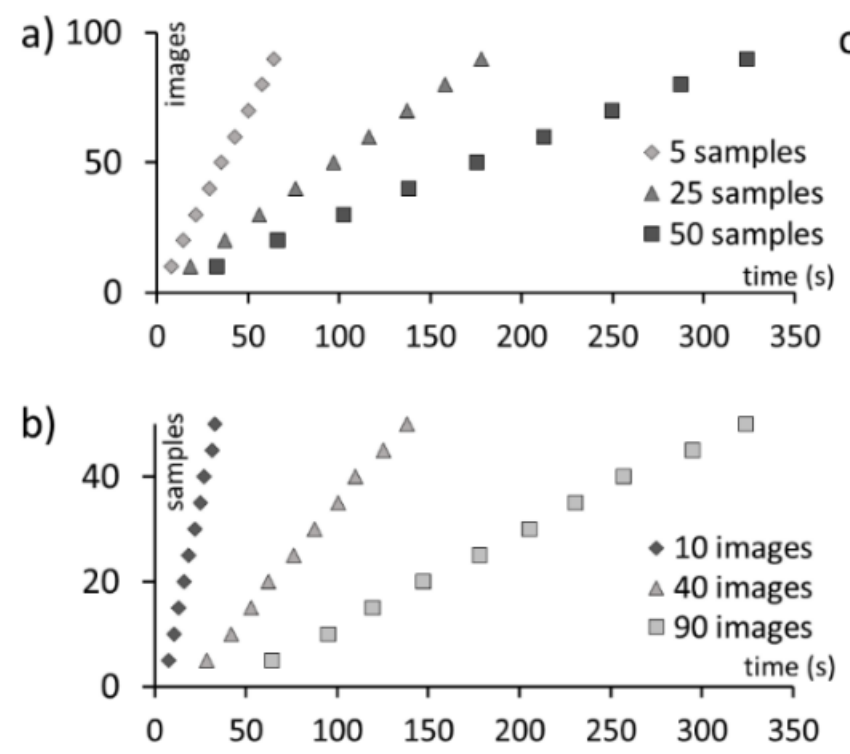

$$
\begin{aligned}
& \text { c) } \Delta t=2.151 \times \text { images }+3.1 \times \text { samples } \\
& \text { Adjusted } \mathrm{R}^{2}=0.895
\end{aligned}
$$

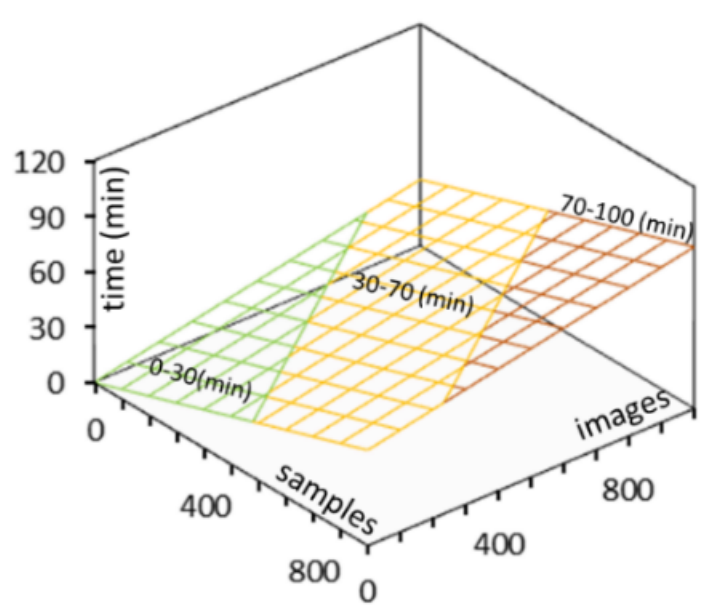

Source: The Authors (2021).

In addition to the visual evidence, all the tested conditions presented a strong linear correlation $\left(0.996<\mathrm{R}^{2}<0.999\right.$; Figure 5.a and 5.b), suggesting that a linear multivariate regression model is appropriate to represent the time demand of the algorithm, regarding the number of images and samples (adjusted $\mathrm{R}^{2}=0.895$; Figure 5.c). The ratio of the $\beta_{1}$ coefficient to the $\beta_{2}$ coefficient indicates that the number of images increases the time demand $44.12 \%$ slower than the number of samples; a positive outcome given that the number of images is the only dimension that grows indefinitely in a typical monitoring scenario. Another theoretical concern of the algorithm is the time complexity related to the sample selection method. Rather than testing the fitness of a given window as a potential control sample, and only then calculating the average reflectance, the method applied takes advantage of the algebraic implementation of the convolution filter (TOMILIERI; LU, 1997). After reading all images as two-dimensional arrays, the algorithm defines all unelectable entries as nonnumeric data. Therefore, all subsequentially operations result in a non-numeric entry, which is automatically excluded from the identification of the pixel with the smallest Euclidean distance, avoiding the need for multiple restriction tests.

Due to the association of restrictions criteria to non-numeric data, the algorithm is already able to filter off samples where there is a lack of good quality DNB or MODIS data, resulting in a gap in the time series. Moreover, the restrictions are all individually stored in arrays that can be retrieved based on the selected control sample coordinates. This allows the user to set quality flags to the output data, indicating what step has coerced the data to a non-numeric format, or even retain the values of the metrics needed for the processing methods and sample selection.

\subsection{Algorithm's outputs}

Figure 6 displays examples of the algorithm's main outputs. Several relevant observations can be pointed out through a visual inspection of both averaged radiance time series (Figure 6a.2 and b.2). Regarding the averaged radiance level of the ROIs, it is clear that different roadways have distinct nominal radiances. While the seven-year time series of the BR-116 roadway shows values ranging from about 2.5 to 7.5 $\eta \mathrm{W} / \mathrm{cm}^{2}$.sr, BR-353's has averaged radiance values barely higher than $0.4 \eta \mathrm{W} / \mathrm{cm}^{2}$.sr, the very same range observed in most of the control sample's time series. Likewise, Cao and Bai (2014) found averaged radiance 
values ranging from 2 to $4 \eta \mathrm{W} / \mathrm{cm}^{2}$.sr after analyzing daily DNB's radiances from a bridge section over the San Francisco Bay, California. These results indicate that it might be meaningless to define thresholds to separate lit from unlit areas since there is a relatively wide range of mixture in radiance levels from the background radiance and dim or transient lit areas.

Figure 6 - Location (a.1, b.1, c) and radiance level time series (a.2, b.2) of different ROIs and their respective control
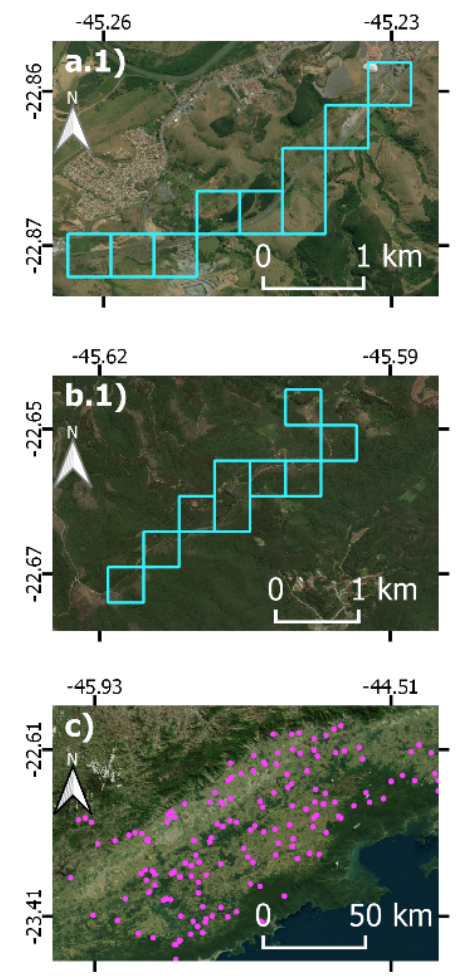
samples.

a.2) Presidente Dutra Roadway (BR-116)

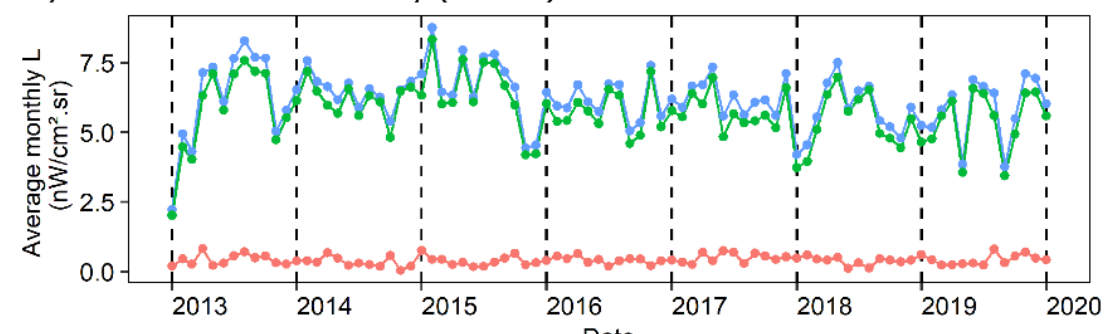

b.2) Major Pereira Roadway (BR-353)

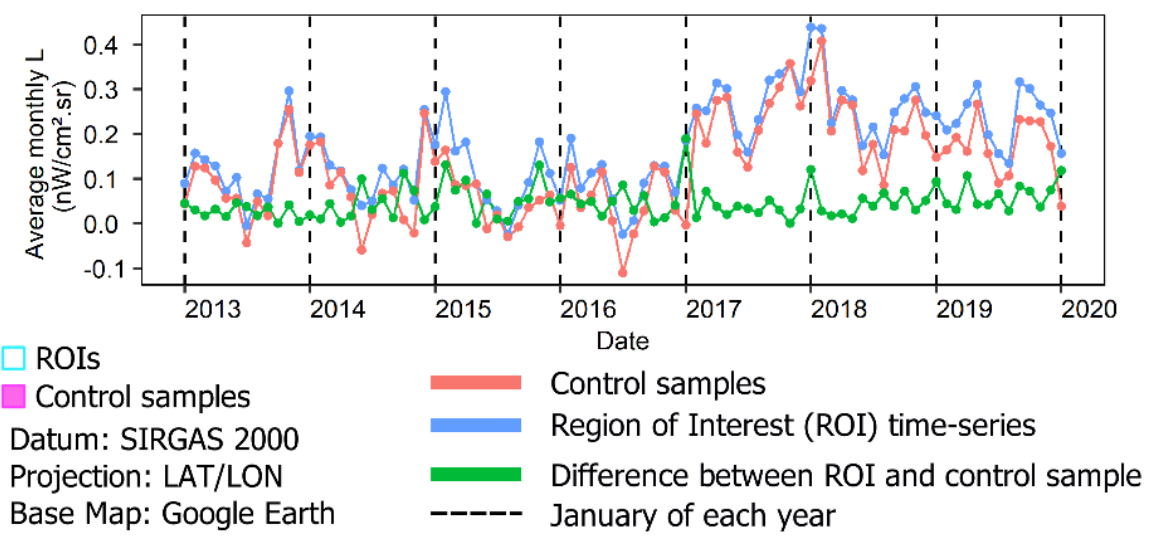

Source: The Authors (2021).

When it comes to heavy traffic roadways, such as the BR-116, the difference between the ROI's and the control samples' averaged radiance does not seem to change the time series' aspect (Figure 6a.2). Even though, after the subtraction, the resulting time series does present some relevant differences if compared with the original one, mainly expressed as shifts in the direction of the series in several pairs of months. The changes in the time series aspect are clearer when observing roadways with a nominal dimmer averaged radiance. In Figure $6 \mathrm{~b} .2$, a major increase in the average monthly radiance is observed from 2017 onwards. Without taking account of the control samples' time series, it could be wrongly interpreted there was a relevant change in the vehicles' regime; or even a restructuring of the outdoor lights of nearby settlements. A probable reason for the observed upward step in the radiance level of unlit areas and low-traffic roadways, 2017 onwards (Figure 4 and Figure 6b.2), is the change of reference of dark offset term from ocean to a space view (ELVIDGE et al., 2020); which can be handled by the algorithm without issues.

Next efforts should give considerable attention to methods for estimating uncertainties regarding the elected control samples. In this sense, the Euclidian distance metric itself should provide a good measure of the control sample's quality, for it is a direct measurement of how alike are the control sample and the ROI.

\section{CONCLUSION}

This paper presents the theoretical approach and the implementation strategy used on the elaboration of an algorithm able to access meaningful unlit control samples of monthly NTL composites based on its spectral response and restrictions criteria. An overview of the algorithm's empirically estimated time complexity showed that all the operations established by the code can be executed in a linear form. Currently, 85 monthly NTL composites are available to be ingested in a time series analysis, but this number will grow 
undefinedly. Moreover, daily processed nighttime images from the DNB sensor will be made available by NASA's Black Marble project soon (blackmarble.gsfc.nasa.gov/), stressing the need for algorithms that can be applied efficiently. In this instance, different datasets will certainly call for different likelihood metrics and restriction criteria; nonetheless, they all can take advantage of the conceived structure of the presented algorithm.

By comparing the time series of roadway sections and spectrally similar background areas identified by the proposed algorithm, it was confirmed that changes in radiance levels of roadways are not all associated with traffic flow at night. The results show that in the consideration of the VIIRS/DNB monthly vem composites as a dataset able to express quantitative information about the traffic of vehicles at night, the analysis of control samples is a necessary step. Whether variations in traffic flow can be detected by the VIIRS/DNB monthly composites, what are the limitations when estimating traffic flow regarding the local crossing time, and what is the effect of the COVID-19 outbreak over the traffic flow at night are scientific questions that will be addressed in future works.

\section{Acknowledgements}

This study was financed in part by the Coordenação de Aperfeiçoamento de Pessoal de Nivel Superior - Brasil (CAPES) - Finance Code 001. The authors would also like to acknowledge the contributions of both anonymous reviewers, who provided excellent instructions, critics and corrections about the manuscript's content.

\section{Authors' Contributions}

All authors were equally responsible for the conceptualization of this article. Data curation and formal analysis of nighttime lights-related data were performed by G. R. B and G. C. G; Data curation and formal analysis of traffic- and roadways-related data were performed by A. C. F. S, A. P. D, S. A., and L. M. O; The article's methodology was designed by G. R. B. and critically reviewed by all authors; G. R. B, G. C. G, and L. M. O. were responsible for the algorithms' coding; S. A. was responsible for the project administration and supervision of the article; The article's original draft was made by G. R. B., critically reviewed, and edited by all authors, who also approved the revised version of the manuscript.

\section{Conflicts of Interest}

The authors declare no conflict of interest.

\section{References}

BAATZ, M. AND SCHÄPE. Multiresolution Segmentation: an optimization approach for high quality multi-scale image segmentation. In: Angewandte Geographische Informations-Verarbeitung, XII, Karlsruhe, Germany, p. 12-23, 2000.

CAO, C.; BAI, Y. Quantitative Analysis of VIIRS DNB Nightlight Point Source for Light Power Estimation and Stability Monitoring. Remote Sensing, v. 6, n. 12, p. 1 - 16, 2014.

CHANG, Y.; WANG, S.; ZHOU, YI; WANG, L.; WANG, F. A Novel Method of Evaluating Highway Traffic Prosperity Based on Nighttime Light Remote Sensing. Remote Sensing, v. 12, n. 1, p. 1-22, 2019.

CHANGE, C., HEINZ, D. C. Constrained Subpixel Target Detection for Remotely Sensed Imagery. IEEE Transactions on Geoscience and Remote Sensing, vol. 38, n. 3, p.1144-1159, 2000.

KOKALY, R.F., CLARK, R.N., SWAYZE, G.A., LIVO, K.E., HOEFEN, T.M., PEARSON, N.C., WISE, R.A., BENZEL, W.M., LOWERS, H.A., DRISCOLL, R.L., AND KLEIN, A.J. USGS Spectral Library Version 7: U.S. Geological Survey Data Series 1035, 61 p., 2000. 
ELVIDGE, C. D., BAUGH, K., ZHIZHIN, M., HSU, F. C., GHOSH, T. VIIRS nighttimes lights. International Journal of Remote Sensing, v. 38, n. 21, p. 5860-5879, 2017.

ELVIDGE, C. D., ZHINZHIN, M., BAUGH, K., HSU, F. Automatic Boat Identification System for VIIRS Low Light Imaging Data. Remote Sensing, v. 7, p. 3020 - 3036, 2015 a.

ELVIDGE, C. D., ZHINZHIN, M., BAUGH, K., HSU, F., GHOSH, T. Methods for Global Survey of Natural Gas Flaring. Energies. v. 9, n. 14, p. 1-15, 2015 b.

ELVIDGE, C. D.; HSU, F.; M. ZHIZHIN, GHOSH, T.; TANEJO, J.; BAZILIAN, A. Indicators Of Electric Power Instability From Satellite Observed Nighttime Lights. Remote Sensing, v. 12, n. 19, p. 1 -35, 2020.

FORTALEZA, C. M. C. B., GUIMARÃES, R. B., ALMEIDA, G. B., PRONUNCIATE, M. AND FERREIRA, C. P. Taking the inner route: spatial and demographic factors affecting vulnerability to COVID-19 among 604 cities from inner São Paulo State, Brazil. Epidmiology and Infection, v. 148, n. 118, p. 1-5, 2020.

GOMES, C., RESCHILIAN, P. R., UEHARA, A. Y. Perspectives of the Regional Planning of Paraíba Valley and North Coast: Milestones and Institutionalization of the Metropolitan Region in the Action Plan of the Macro-metropolis of São Paulo. Brazilian Journal of Urban Management, v.10, n.1, p.154-171, 2018.

HUETE, A. R., JACKSON, R.D., POST, D.F. Spectral response of a plant canopy with different soil backgrounds. Remote Sensing, v. 17, n. 1, p. 37-53, 1985.

INSTITUTO BRASILEIRO DE GEOGRAFIA E ESTATÍSTICA (IBGE). (2019). Base Cartográfica Contínua do Brasil, escala 1:250.000, version 2019. Available at: $<$ https://www.ibge.gov.br/geociencias/downloadsgeociencias/cartas_e_mapas/bases_cartograficas_continuas/bc250.html >. Accessed on: 28 aug. 2020.

INSTITUTO BRASILEIRO DE GEOGRAFIA E ESTATÍSTICA (IBGE). MAPEAMENTO DE RECURSO NATURAIS DO BRASIL - ESCALA 1:250.000: macrocaracterizacao regioes fitoecologicas, 2018. Available at: $<$ https://geoftp.ibge.gov.br/informacoes_ambientais/vegetacao/mapas/brasil/ > . Accessed in: 15 Apr. 2020.

KYBA, C., GARZ, S., KUECHLY, H., MIGUEL, A., ZAMORANO, J., FISCHER, J., HÖLKER, F. HighResolution Imagery of Earth at Night: new sources, opportunities and challenges. Remote Sensing, v. 7, n. 1, p. 1-23, 2014.

LEVIN, N. The impact of seasonal changes on observed nighttime brightness from 2014 to 2015 monthly VIIRS DNB composites. Remote Sensing of Environment, v. 193, p. 150-164, 2017.

LEVIN, N. AND ZHANG, Q. A global analysis of factors controlling VIIRS nighttime light levels from densely populated areas. Remote Sensing of Environment, v.190, p.266-282, 2017.

MAPBIOMAS. MapBiomas Project - Collection 5 of the Annual Land Use Land Cover Maps of Brazil, 2021. Available at: < https://mapbiomas.org/>. Accessed on: 19 apr. 2021.

MOUW, C. B. ET AL. Aquatic color radiometry remote sensing of coastal and inland waters: Challenges and recommendations for future satellite missions. Remote Sensing of Environment, v. 160, p. 15-30, 2015.

POLIVKA, T. N., WANG, J., ELLISON, L. T., HYER, E. J., ICHOKU, C. M. Improving Nocturnal Fire Detection with the VIIRS Day-Night Band. IEEE Transactions on Geoscience and Remote Sensing, v. 54, n. 9, p. 5503-5519, 2016.

SCHAAF, C., Z. WANG. MCD43A4 MODIS/Terra+Aqua BRDF/Albedo Nadir BRDF Adjusted Ref Daily L3 Global - 500m V006. Distributed by NASA EOSDIS Land Processes DAAC, 2015. Available at: $<$ https://doi.org/10.5067/MODIS/MCD43A4.006>. Accessed on: 24 sep. 2020.

TOLIMIERI, R., AN, M., LU, CHAO. Algorithms for discrete Fourier transform and convolution, New York, Springer, 1997.

TUERNER, S.; KURZ, F., REINARTZ, P., STILLA, U. Airborne Vehicle Detection in Dense Urban Areas Using HoG Features and Disparity Maps. IEEE Journal of Selected in Applied Observations and Remote Sensing, v. 6, n. 6, 2013. 


\section{Lead author's biography}

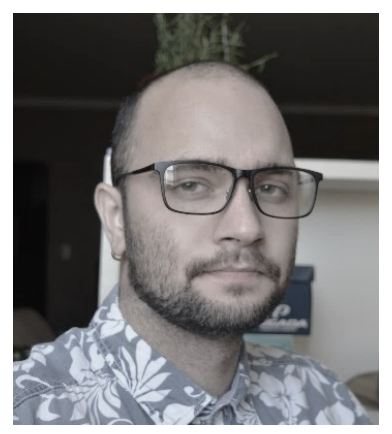

Gabriel da Rocha Bragion was born in São Paulo, Brazil (1994). He holds a bachelor's degree in Environmental Engineering - Federal University for Technology, Brazil (UTFPR), and was an exchange student in the program of Geoenvironmental Science - Trier University, Germany. He also holds a Master's degree in Remote Sensing - National Institute for Space Research, Brazil (INPE). $\mathrm{He}$ is currently a $\mathrm{PhD}$ candidate at the same institution. 